\title{
A TRAVESSIA CULTURAL DE MACABÉA
}

Edgar Cézar Nolasco*

RESUMO: O texto procura acompanhar a travessia da heroína da novela, Macabéa, visando estabelecer uma relação com a própria trajetória da escritora Clarice Lispector. Sobressai na comparação biográfica uma questão de fundo cultural cara à escritora, bem como à sua literatura, qual seja senão a da "judeidade". Na discussão aqui proposta, entende-se que tal aproximação só pode se dar de modo metafórico, uma vez que a escritora não tratou do assunto de forma aberta em seu projeto intelectual, ou seja, não assumindo publicamente sua condição de judia. Todavia, entende-se que tal condição se inscreveu à revelia da intelectual por todo seu projeto literário.

PALAVRAS-CHAVE: A hora da estrela; Clarice Lispector; Judeidade.

E houve tudo o mais que não sei, e que é o caldo de cultura de qualquer história.

A explicação inútil Clarice Lispector

A travessia retirante de Macabéa espelha, de forma especular, tanto a travessia bíblica dos Macabeus, ${ }^{1}$ quanto a travessia pessoal da própria escritora Clarice Lispector. Reconheço, entretanto, que, apesar de tratá-las aqui de forma separadas, a travessia biográfica

* Doutor pela Universidade Federal de Minas Gerais (UFMG). Professor da Universidade Federal de Mato Grosso do Sul (UFMS), onde leciona no PPGMEL e na graduação em letras.

${ }^{1}$ Ver BÍBLIA SAGRADA. Macabeus (Livros I e II). 
da escritora já se encontra, historicamente falando, dentro da travessia dos judeus/macabeus. Ao valer-me da crítica biográfica, minha leitura distancia-se de outras leituras críticas aqui mencionadas, pois entendo que mesmo a aproximação da história de Macabéa com a dos Macabeus já se dá atravessada pela história de vida da escritora. Logo, ler aquelas implica ler esta, mesmo que metaforicamente. ${ }^{2}$

Antes de mais nada, devo dizer que a relação do judaísmo e da literatura de Clarice se apresenta mais como uma problemática de recepção crítica. Diferentemente do que postulam alguns estudiosos sobre o assunto, sobretudo quando forçam e amarram tal relação, penso mesmo que se pode até ler sua literatura sob tal rubrica étnica, mas é sempre bom lembrar que a própria Clarice parece deixar-nos claro que essa não é a condição para compreender sua obra:

Eu sou judia você sabe. Mas não acredito nessa besteira de judeu ser o povo eleito de Deus. Não é coisa nenhuma. Os alemães é que devem ser porque fizeram o que fizeram. Que grande eleição foi essa, para os judeus? Eu, enfim, sou brasileira, pronto e ponto. ${ }^{3}$

Entretanto, e ao mesmo tempo, que contradição: eu sou judia, eu sou brasileira, tão ao estilo clariceano, é, na verdade, mais do que uma negação; é, pois, uma denegação - estratégia recorrente da qual Clarice se vale por toda sua vida literária, sobretudo para tirar proveito para a criação. Exemplo dessa denegação dá-se em suas relações com seus possíveis amigos literários com os quais dialoga esquecendo-se sempre de mencionar o nome da obra

\footnotetext{
2 Acerca da questão da "judeidade" na obra da escritora Clarice Lispector, partilho da ideia de que ela tratou do assunto de forma subliminar, valendo-se mesmo de uma denegação, ao invés de tratar do assunto de forma clara e incisiva. Não acho que ela se sentia "envergonhada" para tratar do assunto, nem cheguei a afirmar isso, como dissera equivocadamente seu biógrafo norte-americano Benjamim Moser. Diferentemente do que afirma seu biógrafo - "Suas referências publicadas à sua filiação étnica são tão esparsas..." (MOSER, 2009, p. 24) -, vejo que tais referências não são "esparsas", mas escassas por todo o decorrer de sua obra. Entendo, cada vez mais, que questões dessa natureza biográfica só são mais bem compreendidas e discutidas quando nos valemos dos postulados da crítica biográfica. Aliás, nesse tocante, o biográfico norte-americano força, literalmente, a barra ao articular vida e obra da escritora, beirando, por conseguinte, o simplismo diante de questões sérias como a da "judeidade", por exemplo, questão esta, inclusive, tratada com uma certa reserva por parte da escritora, como já mostramos em nosso livro Restos de fiçãa (2004) e com certeza desconhecido pelo crítico.
}

${ }^{3}$ Cf. Remate de Males (9), p. 207. 
lida ou até mesmo o do autor "amigo". Bem ao gosto de Clarice, entrevê-se, na passagem citada, um jogo, um mascaramento, um fingimento pensado, estudado mesmo, e durante toda a vida até ali (a entrevista é concedida um ano antes de sua morte, em 1976), assim como teve o cuidado de fabricar várias histórias envoltas com a sua personalidade que contribuíram para sua persona literária.

Nelson Vieira, no texto "Uma mulher de espírito", depois de constatar que poucos críticos consideravam importante a relação da herança judaica da escritora com sua ficção e que a própria Clarice evitava trazer a público seus antecedentes judaicos, diz que "sua insistência clamorosa em ser brasileira, em pertencer à cultura e à literatura brasileira, indica que decidiu em sã consciência minimizar sua etnicidade" (1998, p. 18). Sem querer discordar do crítico, vemos aí que ele confiou demais na encenação da escritora, sobretudo quando afirma que ela decidiu em sã consciência minimizar sua etnicidade, porque, na verdade, não é nada em sã consciência. Antes, isto sim, vemos encenar-se aí mais um daqueles fingimentos tão ao gosto da escritora, armadilhas de representação da qual ela mesma se viu fisgada. "Esclarecimentos, explicação de uma vez por todas" (LISPECTOR, 1984a, p. 498-499) é título de uma crônica em que ela procura explicar, tornar público - na tentativa de esclarecer todas as dúvidas sobre sua pessoalidade - as características que nela poderiam soar como estrangeiras. Explicações como as esclarecidas na crônica só contribuíram ainda mais para descentrar a imagem fabricada que se criou em torno da figura da escritora. Assim, todo esse mundo que se encena em torno de Clarice leva-nos a constatar que ela mesma, de forma ardilosa e pensada, tratou de construí-lo, mesmo quando teve de negar o que mais afirmava. Ou seja, não se cansou de dizer que não se considerava escritora, que não escrevia literatura, que era "feliz de pertencer à literatura brasileira por motivos que nada têm a ver com literatura, pois nem ao menos sou uma literata ou uma intelectual" (LISPECTOR, 1984a, p. 151-153). Constatações como essas contribuem para desmascarar a denegação que Clarice faz em torno, por exemplo, de sua judeidade e de suas possíveis amizades literárias. 
Nelson Vieira diz, de forma que nos interessa: "ao abordar Lispector e sua obra de um ponto de vista judaico, reafirmo minha crença de que vida e literatura, autor e texto ligam-se culturalmente - de que juntos contribuem para uma visão de mundo" (1998, p. 18). É esse campo minado entre a vida e a ficção, ou seja, atravessado por ambas, simultaneamente e metaforicamente, que defendo aqui, sem entender que precisaria estar atrelado a "um ponto de vista judaico". Vieira radicaliza e diz que "o apagamento da herança étnica de Lispector criou uma espécie de cegueira cultural e crítica que obscurece a singularidade de sua ficção" (1998, p. 18-19). Antes entendo que quando se levam em conta traços culturais, biográficos do sujeito escritor, ou seja, quando se toma vida e ficção nas mesmas proporções, pode-se fazer uma leitura crítica melhor, culturalmente falando.

Agora se deve tomar cuidado ao trabalhar com tal relação para não incorrer em aproximações equivocadas e forçadas, como esta do próprio Vieira: "em Um sopro de vida, a narradora Ângela é a própria Lispector, ponto particularmente claro por referências a outros escritos da autora e a seus detalhes biográficos" (VIEIRA, 1998, p. 21).

Berta Waldman, em importante leitura sobre o livro $A$ hora da estrela, estabelece relação entre Macabéa e o judaísmo, mas por nenhum momento sequer alude à metáfora primordial da condição de estar em diáspora, estar em trânsito, nascer em trânsito, transitar entre países e estados brasileiros, a condição de sentir-se "estrangeiro" - que marca do começo ao fim a vida pessoal e cultural da escritora. Apesar de dizer que "a família Lispector transitará de Maceió a Recife e daí ao Rio de Janeiro, demarcando, desde o início, uma experiência de deslocamento e nomadismo que pautará a vida e a obra da escritora" (WALDMAN, 2003, p. 93-104), e de seu texto ter por título "O estrangeiro em Clarice Lispector”, Waldman desconsidera o traço biográfico que rasura a história e o texto de $A$ hora da estrela que é, a nosso ver, porta de entrada para uma leitura, por exemplo, sobre a questão cultural proposta pelo livro. Waldman lembra-nos que "há uma pista no nome da protagonista e também em seu nomadismo que permite estabelecer uma relação entre ela e o judaísmo" (2003, p. 96). 
Pensamos, entre parênteses, que tal relação se amplia, se revaloriza e recebe uma ressignificação quando aí entrevemos a própria vida da escritora. A constatação de que Macabéa alude ao Livro dos Macabeus, bem como seu nomadismo são, na verdade, signos vicários da condição em trânsito que marcou a vida da própria escritora. Assim, é como se a história de Macabéa estivesse colada, "montada nos ombros" de Clarice, como se uma delas passasse para a outra margem pela travessia única, como se fosse uma a continuidade da outra - semelhantemente ao velho da historieta enxertada dentro de $A$ hora da estrela que, passada a travessia nos ombros do moço, disse-lhe que era "tão bom estar aqui montado como estou que nunca mais vou sair de você" (LISPECTOR, 1984b, p. 28).

Clarice Lispector, em crônica sobre suas viagens, narra a primeira que "foi com menos de dois anos de idade, da Alemanha (Hamburgo) a Maceió [Recife, diz ela]. (...) Nada sei sobre essa viagem de imigrantes: devíamos todos ter a cara dos imigrantes de Lazar Segall” (LISPECTOR, 1984a, p. 545). Como se vê, ela nasce em trânsito, na Ucrânia, e chega a Maceió, mudando-se depois para Recife, onde vive e se cria, indo só mais tarde para o Rio de Janeiro, que, nas suas palavras, "era a cidade grande e cosmopolita que, no entanto, em breve se tornava para mim brasileira-carioca" (LISPECTOR, 1984a, p. 498499). Ucraniana, brasileira, nordestina, carioca, judia e macabéa - eis um retrato de Clarice Lispector.

Também vai ser nessa cidade grande e cosmopolita que a retirante Macabéa, tendo deixado o Nordeste para trás, vai se encontrar, ou ser encontrada, e ter suas fracas aventuras contadas "numa cidade toda feita contra ela". (LISPECTOR, 1984b, p. 21). Metaforicamente falando, podemos dizer que Macabéa, enquanto figura que alude à dispersão do povo judeu (família Lispector judia), dá continuidade (acompanhando sua criadora) à travessia de Clarice de Maceió/Recife ao Rio de Janeiro. Resta-nos observar aí, nessa trajetória, que, devido à sua estada em Alagoas, e, sobretudo em Recife, Clarice deixa o nordeste impregnada, travestida de uma macabéa alagoana.

Perguntada quando foi buscar dentro dela mesma a história de Macabéa, Clarice sentenciou: 
- Eu morei no Recife; eu morei no nordeste; eu me criei no nordeste. E depois, no Rio de Janeiro, tem uma feira de nordestinos no Campo de São Cristóvão e uma vez eu fui lá e peguei o ar meio perdido do nordestino no Rio de Janeiro. Daí começou a nascer a ideia. ${ }^{4}$

Da passagem, sobressaem duas questões que podem ser pensadas: uma que era público que Clarice ia regularmente à feira de nordestinos em São Cristóvão; a outra, é que sua fala, na entrevista, pode estar filtrada pelo que escrevera na novela, uma vez que tinha acabado de escrevê-la quando concedeu a entrevista. Tais questões, atravessadas por traços biográficos, ficam mais evidentes quando se compara, por exemplo, o que dissera a escritora com o que escrevera o autor Rodrigo S.M.: "é que numa rua do Rio de Janeiro peguei no ar de relance o sentimento de perdição no rosto de uma moça nordestina. Sem falar que eu em menino me criei no Nordeste" (LISPECTOR, 1984b, p.18). Ou: "se sei quase tudo de Macabéa é que já peguei uma vez de relance o olhar de uma nordestina amarelada. Esse relance me deu ela de corpo inteiro” (LISPECTOR, 1984b, p.66).

Segundo Nádia Gotlib, “ali mesmo na feira sentou-se num banco e escreveu umas quatro ou cinco páginas sobre sua personagem” (GOTLIB, 1995, p. 473). Fecha essa aparente curiosidade o fato de que foi também na mesma feira que Olímpico foi comprar pimenta-malagueta para impressionar sua namorada Glória (Cf. LISPECTOR, 1984b, p. 75).

Percebemos que ocorre aí uma "dramaturgia da subjetividade", na feliz expressão de Lúcia Helena, porque a biografia da escritora aparece sobrepondo-se e tecendo ao mesmo tempo as biografias dos outros dois nordestinos - o escritor-autor Rodrigo S.M. e a personagem-protagonista Macabéa. Se pelo lado histórico-biográfico-cultural podemos dizer, sempre metaforicamente, que Clarice é muito mais Macabéa; pelo lado biográficoliterário ela é muito mais Rodrigo S.M. No tocante à representação, máscaras, fingimentos e a denegação que envolvem a vida e a ficção da escritora chegam ao seu máximo no livro

${ }^{4}$ CLARICE LISPECTOR. (vídeo) Programa "Panorama Especial" [transcrição livre]. 
A hora da estrela, uma vez que aí qualquer resquício de corpo do "eu" autoral é rasurado até o limite.

A ponto de que basta pensarmos que, em algum lugar da ficção, ali poderia estar um traço de pessoalidade da escritora sem máscara, sem fingimento, para que uma nervura em filigrana de subjetividade se tinja manchando toda a cena ficcional.

Quero voltar agora a um comentário que Clarice faz sobre sua primeira viagem, quando diz que "devíamos todos ter a cara dos imigrantes de Lasar Segall”. Tal imagem, retrato impressionista feito por ela mesma, é sugestiva e significativa, sobretudo quando se pode contrapô-la às fotografias da família Lispector, assim como ao retrato ficcional de Macabéa feito pela própria escritora. Se em tal comparação de Clarice, "há um tom amargurado, seco, na referência que faz ao ‘quadro’ de Lasar Segall, de que se vê personagem” (GOTLIB, 1995, p. 129), conforme constata Nádia Gotlib; na verdade, não é bem isso o que mais nos chama a atenção. O olhar de soslaio, perdido, sem diretiva e triste das figuras imigrantes de Segall encontra ressonância perfeita no olhar desprendido da fotografia da família Lispector de imigrantes e judeus.

Teresa Cristina M. Ferreira, ao comentar sobre "quem sabe a última foto antes da família embarcar para o Brasil", observa "que não há nem mesmo o esboço de um sorriso; as três meninas reproduzem os olhares sisudos dos pais" (FERREIRA, 1999, p. 27). É possivelmente sobre essa foto da família que Clarice faz o referido comentário. Nela, a futura escritora tem não mais que um ano de idade e ainda se chama Haia, que em hebraico significa "vida". A pequena infante só vai receber o nome Clarice no Brasil. Mas é sugestivo lembrar que a matéria (vida) que mais vai faltar à heroína Macabéa é a que, talvez não por acaso, é tingida ao final pela morte abrupta que atinge, inclusive no mesmo ano (1977), sua própria mentora. ${ }^{5}$

Nádia Gotlib, por sua vez, ao comentar sobre uma outra foto da família Lispector, afirma que:

${ }^{5}$ Lê-se em A hora da estrela: "A morte que é nesta história o meu personagem predileto" (p. 95). 
sente-se a força pungente do olhar da mãe, que certamente é o mais conturbado do conjunto. (...) O sofrimento que lhe causou a doença marcaria profundamente todas as pessoas da família. O seu olhar forte parece, por esse motivo, ligar-se ao de Clarice, que também olha para a câmara imersa numa intranquilidade, porém mal definida. Em mistério. A sugerir ambiguidades: mergulhada em distância e, ao mesmo tempo, com certa perturbação (GOTLIB, 1995, p. 67).

Também nessa foto, semelhante à anterior, só que agora noutras condições, o olhar é para longe, sem diretiva, de soslaio, circunspecto. Todas as cinco figuras parecem sofrer de uma tristeza crônica, mesmo encontrando-se agora a família instalada no Brasil (Recife), talvez porque, de forma inconsciente, se lembrem da fotografia anterior que teve seu lugar reservado no passaporte da família em diáspora. Nessa foto tirada em terras nordestinas, a menina Clarice aparece um "tanto perdida, espremida pelos braços fortes da mãe", talvez já antecipando, de forma alusiva, um retrato $3 \times 4$ em preto e branco da jovem com ferrugem, Macabéa, tirado na cidade toda feita contra ela, o Rio de Janeiro.

Lembramos que o autor Rodrigo S.M., antes de começar de fato a nos contar a história de sua personagem, diz que é preciso tirar vários retratos da alagoana (Cf. LISPECTOR, 1984b, p. 47). Desses retratos, destacamos aquele que dialoga diretamente com o retrato de Macabéa feito por Clarice na entrevista. Enquanto Rodrigo S.M. diz "que numa rua do Rio de Janeiro peguei no ar de relance o sentimento de perdição no rosto de uma moça nordestina. Sem falar que eu em menino me criei no Nordeste” (LISPECTOR, 1984b, p. 18), Clarice reitera: "eu morei no Nordeste; e "uma vez eu fui lá e peguei o ar meio perdido do nordestino no Rio de Janeiro". ${ }^{6}$ Repetimos tais passagens tão somente para contrapor e dizer que o ar de perdição, de fracasso, de ruína, de abandono e de desolação que os dois veem na nordestina Macabéa é o mesmo - considerando o tanto que as fotografias estão atravessadas por nosso olhar - que encontramos nas referidas fotos dos retirantes judeus da família Lispector. Cabe-nos complementar que assim como as fotografias podem 
estar atravessadas pelo olhar da recepção, ${ }^{7}$ também o sentimento de estar perdido da alagoana Macabéa no Rio de Janeiro está comprometido historicamente pelo olhar dos retirantes nordestinos Rodrigo S.M. e Clarice Lispector.

Os vários retratos de Macabéa oferecidos por seu autor complementam-se com os comentários do próprio namorado Olímpico, como: “a cara é mais importante do que o corpo porque a cara mostra o que a pessoa está sentindo. Você tem cara de quem comeu e não gostou, não aprecio cara triste, vê se muda - (...) vê se muda de 'expressão"' (LISPECTOR, 1984b, p. 61). Já a expressão de Rodrigo de que Macabéa tinha uma "cara um pouco inexpressiva demais" (LISPECTOR, 1984b, p. 69) pode ser contraposta a uma fotografia que pode ser da própria Clarice e que foi por ela comentada dentro da ficção $A$ paixão segundo G.H. Ao comentar tal fotografia, diz G.H./ C.L. que, ao olhar de relance o rosto fotografado, viu naquele rosto inexpressivo que o mundo também a olhava de volta inexpressivo (LISPECTOR, 1979, p. 29). E conclui dizendo ver na "sorridente fotografia mal-assombrada de um rosto cuja palavra é um silêncio inexpressivo" e que "todos os retratos de pessoas são um retrato de Mona Lisa” (LISPECTOR, 1979, p. 21). Diríamos que o inexpressivo desses rostos não é tão insignificante assim, porque nos diz das circunstâncias pessoais e culturais de cada uma delas e da própria sociedade. Até mesmo o silêncio aí é expressivo, significativo, por nos dizer da travessia cultural das retirantes. E, aqui, lembro-me de uma descrição da escritora feita por sua amiga e também escritora Nélida Pinõn:

[...] um rosto russo e melancólico, desafiante e misericordioso. Neste rosto de Clarice convergiam aquelas peregrinas etnias que venceram séculos, cruzaram Oriente e Europa, até que ancorassem no litoral brasileiro, onde veio ela afinal tecer ao mesmo tempo o ninho de sua pátria e o império de sua linguagem (PIÑON apud VIEIRA, 1998, p. 31).

Fechando os parênteses, diríamos que culturas nacionais e estrangeiras, traços biográficos, diálogos com obras da humanidade e com as Escrituras Sagradas, crenças, cultura

${ }^{7}$ Vale a pena conferir BARTHES. A câmara clara. 
de massa e história de Cordel, estrelas de cinema hollywoodiano, cultura midiática etc., fazem o caldo cultural que se amalgama em $A$ hora da estrela. Sobre isso, retomo Berta Waldman, que confirma que "o sincretismo, ponto de cruzamento de crenças, tradições e culturas, típico de um país multiétnico e multicultural como é o Brasil, fica flagrante no universo clariciano" (WALDMAN, 2003, p. 102).

É sabido que os Macabeus continuaram fiéis à Lei de Moisés. Também Macabéa confiou cegamente nas palavras da cartomante: "Macabéa ficou um pouco aturdida sem saber se atravessaria a rua pois sua vida já estava mudada. E mudada por palavras - desde Moisés se sabe que a palavra é divina” (LISPECTOR, 1984b, p. 90). E Clarice, perguntaríamos, confiou na palavra? Bem, vejamos o que ela mesma disse sobre o assunto:

Depois eu fui a uma cartomante e imaginei: ela me disse várias coisas boas que iam me acontecer - e imaginei, quando tomei o táxi de volta, que seria muito engraçado se um táxi me pegasse e eu morresse depois de ter ouvido essas coisas boas. Então daí foi nascendo também a trama da história. ${ }^{8}$

Diríamos, por último, que Clarice blefa, com relação à história de Macabéa, e é traída pela palavra. Blefa sobre a história de Macabéa porque, apesar de reconhecer que desde Moisés sabe-se que a palavra é divina e de dizer que "a cartomante lhe decretara sentença de vida”, (LISPECTOR, 1984b, p. 90) opta pela morte. Ou seja, aí já se iniciara sua traição pela palavra, quando transfere para a criatura Macabéa o que imaginara que poderia acontecer consigo mesma - seria muito engraçado morrer depois de ouvir todas aquelas coisas boas. Parece, na verdade, que Clarice não escuta sua própria palavra que (in)conscientemente lhe prescrevia o gran finale abrupto de sua verdadeira morte. ${ }^{9}$

${ }^{8}$ CLARICE LISPECTOR (vídeo). Programa "Panorama Especial” [transcrição livre].

${ }^{9}$ Cf. NOLASCO. Restos de fição: a criação biográfico-literária de Clarice Lispector, principalmente o cap. II, onde defendemos a ideia de que a gênese da ficção clariciana já se dá atravessada pelo traço biográfico-cultural. 


\section{THE CULTURAL TRANSFER OF MACABÉA}

ABSTRACT: The text seeks to accompany the crossing of the heroine of the novel Macabéa, aiming to establish a relationship with the very trajectory of the writer Clarice Lispector. In the biographical comparison, a question of cultural background to the writer, as well as to her literature, other than that of "Jewishness." In the discussion proposed here, it is understood that such an approach can only take place metaphorically, since the writer did not address the subject openly in her intellectual project, ie, not publicly assuming her status as a Jewess. However, it is understood that this condition was inscribed in the absence of the intellectual throughout his literary project.

KEYWORDS: The Hour of the Star; Clarice Lispector; Jwishness.

\section{REFERÊNCIAS:}

CLARICE LISPECTOR (vídeo). Programa "Panorama Especial". São Paulo, TV 2 Cultura, fev.1977.

FERREIRA, Teresa C. M. Eu sou uma pergunta: uma biografia de Clarice Lispector. Rio de Janeiro: Rocco, 1999.

GOTLIB, Nádia Battella. Clarice: uma vida que se conta. São Paulo: Ática, 1995.

LISPECTOR. Clarice. A descoberta do mundo. 2. ed. Rio de Janeiro: Nova Fronteira, 1984a.

LISPECTOR, Clarice. A hora da estrela. 7. ed. Rio de Janeiro: Nova Fronteira, 1984b.

LISPECTOR, Clarice. A paixão segundo G.H. 7. ed. Rio de Janeiro: Nova Fronteira, 1979.

NOLASCO, Edgar Cézar. Restos de ficção: a criação biográfico-literária de Clarice Lispector. São Paulo: Annablume, 2004.

AREAAS, V; WALDMAN, B. Eppur, Se Muove. ARREMATE DE MALES/Revista do Departamento de Teoria Literária, Campinas, UNICAMP, Vol. 9, p. 161-168, 1989.

VIEIRA, Nelson. In: ZILBERMAN, Regina et al. Clarice Lispector: a narração do indizível. Porto Alegre: Artes e Ofícios, EDIPUC, Instituto Cultural Judaico Marc Chagal, 1998. p. 17-39: Uma mulher de espírito.

WALDMAN, Berta. Entre passos e rastros. São Paulo: Perspectiva; FAPESP; Associação Universitária de Cultura Judaica, 2003. 